\title{
Palmar annular ligament desmitis in horses: retrospective study between desmotomy and desmectomy techniques
}

\author{
Pierre Barnabé Escodro ${ }^{1}$, Priscila Faria Rosa Lopes ${ }^{2, *}$, Fábio Raphael Pascoti Bruhn ${ }^{2}$ \\ ${ }^{1}$ Faculty of Veterinary Medicine, Federal University of Alagoas, UFAL, Viçosa, 57700-000, Brazil \\ ${ }^{2}$ Department of Veterinary Medicine, Federal University of Lavras, UFLA, Lavras 37200-000, Brazil
}

(Received: March 19, 2013; Revised: October 15, 2013; Accepted: October 21, 2013)

\begin{abstract}
This study evaluated two different surgical techniques for the treatment of palmar annular ligament desmitis (PAL) in horses. The group 1 (G1) consisted of 11 Thoroughbred submitted to desmotomy, and G2 of 22 horses that underwent PAL desmectomy. There was no statistically significant difference between mean palmar annular ligament thickness in both groups evaluated $(p=0.800)$. In this study, the horses of G1 had 12 times more chance to return to physical activity, when compared to animals of G2 ( $p=0.033$; O.R. $=12.0$; C.I.95\% $=1,142-126,122)$. Desmectomy was more efficient in promoting the resolution of the injury and the return to sports activity.
\end{abstract}

Keywords : forelimb, equine diseases, lameness, ligament, surgical procedures

The constriction of the superficial digital flexor tendon by the palmar annular ligament (PAL) results in palmar annular desmopathy, which is mostly found in forelimbs of athletic horses. The pathogenesis of the palmar annular desmopathy involves an initial injury that progresses with chronic distal flexor tendinitis and tenosynovitis, as well as blunt trauma, injuries and infections in the palmar aspect of the metacarpophalangeal join $[10,13]$. As a consequence of the injury, it is possible to occur the distension of the flexor tendons sheath and the indirect volume increase of the tendons. Concomitantly, the PAL, that do not adapt somewhat to pathological changes, compresses the tendons and adjacent structures, which creates a restriction of movement and eventually can develop a local inflammatory reaction $[9,11,15]$.

In the distal tendinitis of the superficial digital flexor tendon (SDFT), the pathophysiology becomes similar to those described in the tendon sheaths strains mainly between $2 \mathrm{~B}$ and $3 \mathrm{~B}$ regions, corresponding to the proximal and distal limits of the PAL, respectively. Furthermore, there is also a possibility of adhesion between the tendon and the PAL, during the patient treatment $[1,8,11,12]$. Even in some animals, without apparent tendinitis, the incarceration of the superficial digital flexor tendon by the PAL is disclosed, associated with the tendon healing process, where the increased diameter of the SDFT is diagnosed by ultrasonograhy [6].

The diagnosis is based on the clinical history, clinical presentation and on ancilliary tests, such as ultrasonography and magnetic resonance imaging $[4,5,11]$. The palmar annular ligament desmitis (PALD) may be conservative or surgical, depending on the thickness of the PAL, and the level of local inflammation [2, 10, 11]. According with Thomassian [13], the PAL can be classified as normal, slightly thickened and thickened, corresponding to values of 0.1 to $0.5 \mathrm{~cm}, 0.5$ to $0.8 \mathrm{~cm}$ and greather than $0.8 \mathrm{~cm}$, respectively.

The surgical treatment consists in PAL sky closed desmotomy, according to the technique described by Turner \& McIlwraith [14], or by tenoscopy [3, 7, 11]. A modified Turner \& McIlwraith [14] technique, by Escodro [6], combines the PAL strip removal, termed palmar annular ligament desmectomy. McGhee et al. [10] describes a similar surgical technique, named as palmar annular ligament desmoplasty.

The aim of this study was to compare the effectiveness between PAL desmotomy and desmectomy in horses with palmar annular ligament desmitis, considering the wound dehiscence and the return to sports activities.

It was performed a retrospective study of 33 cases of horses submitted to surgery for the treatment of PALD, at the VetPolo's Veterinary Hospital, located in Indaiatuba, SP, from 2002 to 2008 . The animals had a clinical history of mild to moderate lameness in one of the forelimbs, without any association with other lesions in the locomotor system. All the horses underwent a complete lameness exam. Medical records were reviewed for the retrieval of the information regarding the breed, sex, age, history, clinical and ultrasonographic findings, and postoperative complications.

The soft structures of the dorsal and palmar aspect were evaluated by ultrasound, in the sagittal and transversal planes, with a $7.5 \mathrm{MHz}$ linear transducer. A PAL thickening

*Corresponding author

Tel: +55-82-3214-1905, Fax: +55-82-3214-1069

E-mail: priscila.fr.lopes@gmail.com 
Table 1. Characterization of group 1 (G1) in relation to age, weight and sex

\begin{tabular}{cccc}
\hline \hline Animal number & Weight $(\mathrm{kg})$ & Age (months) & Sex \\
\hline 1 & 426 & 168 & $\mathrm{~F}$ \\
2 & 451 & 96 & $\mathrm{~F}$ \\
3 & 420 & 120 & $\mathrm{M}$ \\
4 & 445 & 60 & $\mathrm{~F}$ \\
5 & 464 & 72 & $\mathrm{~F}$ \\
6 & 396 & 84 & $\mathrm{~F}$ \\
7 & 402 & 84 & $\mathrm{M}$ \\
8 & 438 & 108 & $\mathrm{M}$ \\
9 & 451 & 156 & $\mathrm{~F}$ \\
10 & 406 & 144 & $\mathrm{M}$ \\
11 & 414 & 96 & $\mathrm{~F}$ \\
\hline Mean \pm Standard & $428.45 \pm 22.70$ & $108 \pm 35.19$ & $7 \mathrm{~F}(63.64 \%) /$ \\
Deviation & & & $436.36 \%)$ \\
\hline
\end{tabular}

greater than $0.4 \mathrm{~cm}$ was the sonographic diagnostic criteria adopted to characterize the PALD. Moreover, the presence of hypoecoic areas in the SDFT under the PAL were associated with concurrent tendinitis.

The animals were treated surgically either with PAL desmotomy (group 1; G1) or desmectomy (group 2; G2). The G1 consisted of 11 thoroughbred animals, seven females and four males, inserted in polo activity, with a mean age of 108 \pm 35.19 months and average body weight of $428.45 \pm 22.7$ $\mathrm{kg}$ (Table 1). Six interventions were performed in the right forelimb (RFL) and five in the left forelimb (LFL). The surgery was performed with the animal in the orthostatic position, under a neuroleptoanalgesia routine protocol with acepromazine $(0.05 \mathrm{mg} / \mathrm{kg} / \mathrm{iv})$ and xylazine $(0.5 \mathrm{mg} / \mathrm{kg} / \mathrm{iv})$. The surgical access, about $3 \mathrm{~cm}$ in length, was done in the palmarolateral aspect, immediately dorsal to the proximal limit of the PAL, at a closed-sky procedure (without direct exposure of the PAL). The ligament was sectioned with a tenotome and the skin was sutured using zero monofilament nylon in horizontal mattress suture pattern.

The G2 was composed by 22 horses that underwent PAL desmectomy: 18 Thoroughbred, 2 Mangalarga Marchador, 1 American Trotter and 1 Quarter Horse. Eighteen were females and four males, at an average age of 105,91 \pm 31.46 months and mean body weight of $413.17 \pm 28.75 \mathrm{~kg}$ (Table 2 ). Those animals performed activities of polo, race, pleasure and barrel racing. The total number of interventions in the RFL were 13, and 9 in the LFL. All the procedures were performed under general intravenous or inhalation anesthesia. Horses were premedicated with acepromazine $(0.03 \mathrm{mg} / \mathrm{kg}$, intravenously; IV) and xylazine $(0.5 \mathrm{mg} / \mathrm{kg}, \mathrm{IV})$ and induced with diazepam $(0.1 \mathrm{mg} / \mathrm{kg}, \mathrm{IV})$, followed by ketamine $(2.2 \mathrm{mg} / \mathrm{kg}$, IV). Anesthesia was maintained by the continuous intravenous infusion of a mixture of $500 \mathrm{~mL} 10 \%$ guaifenesin solution, $1 \mathrm{~g}$ ketamine and $500 \mathrm{mg}$ xylazine or isoflurane. In the lateral decubitus, the surgical approach was on the palmaro-
Table 2. Characterization of group 2 (G2) in relation to age, weight and sex

\begin{tabular}{|c|c|c|c|}
\hline Animal number & r Weight (kg) & Age (months) & Sex \\
\hline 1 & 408 & 96 & $\mathrm{~F}$ \\
\hline 2 & 414 & 108 & $\mathrm{~F}$ \\
\hline 3 & 434 & 120 & $\mathrm{~F}$ \\
\hline 4 & 381 & 132 & $\mathrm{~F}$ \\
\hline 5 & 402 & 132 & $\mathrm{~F}$ \\
\hline 6 & 399 & 48 & M \\
\hline 7 & 415 & 60 & $\mathrm{~F}$ \\
\hline 8 & 442 & 132 & $\mathrm{~F}$ \\
\hline 9 & 402 & 84 & $\mathrm{~F}$ \\
\hline 10 & 418 & 84 & $\mathrm{~F}$ \\
\hline 11 & 398 & 60 & $\mathrm{~F}$ \\
\hline 12 & 406 & 144 & M \\
\hline 13 & 378 & 72 & $\mathrm{~F}$ \\
\hline 14 & 414 & 96 & $\mathrm{~F}$ \\
\hline 15 & 443 & 120 & $\mathrm{~F}$ \\
\hline 16 & 402 & 84 & $\mathrm{~F}$ \\
\hline 17 & 385 & 120 & M \\
\hline 18 & 402 & 144 & M \\
\hline 19 & 389 & 72 & $\mathrm{~F}$ \\
\hline 20 & 378 & 120 & $\mathrm{~F}$ \\
\hline 21 & 478 & 132 & $\mathrm{~F}$ \\
\hline 22 & 489 & 108 & $\mathrm{~F}$ \\
\hline $\begin{array}{c}\text { Mean } \pm \\
\text { Standard } \\
\text { Deviation }\end{array}$ & $413.17 \pm 28.75$ & $105.91 \pm 31.46$ & $\begin{array}{c}18 \mathrm{~F}(81.82 \%) / \\
4 \mathrm{M}(18.18 \%)\end{array}$ \\
\hline
\end{tabular}

lateral field with incision extending immediately dorsal to the proximal limit of the PAL, up to proximal basis of the sesamoid bone. The subcutaneous tissue was divulsioned until the exposure of the PAL, removing a strip of $2 \sim 4 \mathrm{~cm}$ length, then, the subcutaneous tissue was closed using a Cushing pattern and 2-0 polygalactin suture, followed by the skin apposition with a 0 monofilament nylon in a simple interrupted suture.

The postoperative period and the rehabilitation were the same for both groups, consisting of an intravenous nonsteroidal anti-inflammatory drug (phenylbutazone at $4 \mathrm{mg} / \mathrm{kg}, \mathrm{IV}$ ), once a day, for four consecutive days and benzathine penicillin $(20,000 \mathrm{UI} / \mathrm{kg}$, intramuscular; IM), every $72 \mathrm{~h}$ in two applications. A solution of $1 \%$ povidone-iodine was used for daily wound cleansing, associated with zinc oxide dressings, heparinoids ointments and compressive bandages for two weeks. After this period, the bandages were removed. From the third day post surgery, all patients had being exercised, twice daily, for $15 \mathrm{~min}$, in order to avoid adhesions of the soft structures.

Potentials associations between the PAL thickeness and the return to sports activity were evaluated in both groups, and the prevalence of surgical wound dehiscence and the return 
Table 3. Mean of Palmar Annular Ligament (PAL) thickness, presence of hypoechoic areas in the superficial digital flexor tendon (SDFT), return to sports and days to return to sports of the horses of G1

\begin{tabular}{ccccc}
\hline \hline Animal number & PAL thickness $(\mathrm{cm})$ & Hypoechoic areas in SDFT & Return to sports & Time to return to sports (days) \\
\hline 1 & 0.62 & Yes & Yes & 120 \\
2 & 0.58 & No & Yes & 90 \\
3 & 0.84 & Yes & Yes & 120 \\
4 & 0.48 & No & Yes & 60 \\
5 & 0.50 & Yes & Yes & 90 \\
6 & 0.74 & Yes & Yes & 120 \\
7 & 0.61 & Yes & Yes & 120 \\
8 & 0.54 & No & Yes & 60 \\
9 & 0.72 & Yes & Yes & 90 \\
10 & 0.58 & Yes & Yes & 90 \\
\hline Mean \pm Standard Deviation & $0.61 \pm 0.11$ & Yes & $7 / 11(63.64 \%)$ & 90 \\
\hline
\end{tabular}

to sports, considering each group. The animals were observed for twelve months post surgery.

The Kolgomorov-Smirnov normality test was applied in the variable timing (days), for the return to sports after the surgical treatment. The lack of normality was used in this variable considering the non-parametric Mann-Whitney test, comparing with the both surgical techniques. The Spearman's rank correlation was tested between the PAL thickeness and the time (days), for the return to sports. The Fischer's exact test was used in order to compare each surgical technique with the return (success) or not (failure) to sports performed previously. Data analysis was performed through PASW Statistics 18.0 (SPSS, USA).

All animals had unilateral lameness grade 1 3 [12] in the pre-surgical moment, with clinical signs such as different intensities of edema in the metacarpal palmarodistal aspect of the affected limb, increased temperature and pain on palpation. A convex contour in the PAL region was observed macroscopically, as reported by Owen et al. [11].

In every single horse occurred exacerbation of lameness when the flexion test was applied in the metacarpophalangeal joint. The lameness decrease, at least 50\%, after palmar metacarpal nerve block with lidocaine chloride. There was no case where lameness was completely absent with the nerve block.

In G1, $72.72 \%(8 / 11)$ of the horses showed hypoechoic areas in the SDFT, corresponding to the proximal border of the PAL. The other animals showed tendon lesions, visible in the ultrasound. In G2, hypoechoic areas were observed in $100 \%(22 / 22)$ of animals, associated or not, to suggestive images of adherences between the proximal edge of PAL and the SDFT. The mean and standard deviation of the PAL thickness for G1 and G2 was $0.611 \pm 0.11 \mathrm{~cm}$ and $0.597 \pm$ $0.17 \mathrm{~cm}$, respectively. There was no statistically significant difference between mean PAL thickness in both groups evaluated $(p=0.800)$ and no significant correlation between the thickness and the time, in days, to the return to sports activ- ity $(p=0.192)$.

The suture dehiscence is among the major postoperative complications in surgical wounds on equine limbs and is common finding in previous literature, those that have been reported to search new materials and procedures which its occurrence were prevented and decreased. Contamination and local infection can lead with chronic septic tenosynovitis, making useless horses to sporting practices [3, 10].

In $\mathrm{G} 1$, no horse had wound dehiscence. However, in G2, $9.09 \%(2 / 22)$ of horses had the wound open spontaneously. In these cases, the healing occurred by second intention, taking an average of 50 days for the complete repair. As final result, the scars formed were worse, aesthetically, than those by first intention. This probably happened because the desmectomy is a more invasive technique compared to desmotomy. Desmectomy requires general anesthesia, which may result in more abrupt movement and cause major complications during the recovery period. This technique, applied with the animal in orthostatic position, is not suitable, due to incision extension and the difficult in accessing the PAL, mainly when it is adhered to the SDFT [6].

$36.36 \%(4 / 11)$ of the horses of G1 did not return or remained in sports activity after 12 months after the surgery. The other animals returned to activity practiced previously, without presenting any episodes of lameness or reduced performance in the period. In the G2, 95.45\% (21/22) of animals returned to the same sport activity level prior to the occurrence of the injury. The average number of days to return to sport in the G1 and G2 was 95.45 and 95 respectively (Tables 3 and 4).

The desmectomy shown to be more effective in promoting the reestablishment of the horses than those animals who had the desmotomy. It was noted that animals submitted to desmectomy had twelve times more chance to return to physical activity than the animals undergoing desmotomy ( $p=0.033$; O.R. $=12.0$; C.I. $95 \%=1,142-126,122)$. Possibly, the desmectomy allowed, besides the better visualization of the sur- 
Table 4. Mean of Palmar Annular Ligament (PAL) thickness, presence of hypoechoic areas in the superficial digital flexor tendon (SDFT), return to sports and days to return to sports of the horses of G2

\begin{tabular}{|c|c|c|c|c|}
\hline Animal number & PAL thickness $(\mathrm{cm})$ & Hypoechoic areas in SDFT & Return to sports & Time to return to sports (days) \\
\hline 1 & 0.55 & Yes & Yes & 110 \\
\hline 2 & 0.52 & Yes & Yes & 90 \\
\hline 3 & 0.67 & Yes & Yes & 90 \\
\hline 4 & 0.72 & Yes & Yes & 120 \\
\hline 5 & 0.69 & Yes & Yes & 60 \\
\hline 6 & 0.54 & Yes & Yes & 90 \\
\hline 7 & 0.54 & Yes & Yes & 70 \\
\hline 8 & 0.46 & Yes & Yes & 80 \\
\hline 9 & 0.38 & Yes & Yes & 90 \\
\hline 10 & 0.80 & Yes & Yes & 120 \\
\hline 11 & 0.45 & Yes & Yes & 120 \\
\hline 12 & 0.52 & Yes & Yes & 120 \\
\hline 13 & 0.60 & Yes & Yes & 120 \\
\hline 14 & 0.68 & Yes & Yes & 70 \\
\hline 15 & 0.90 & Yes & Yes & 70 \\
\hline 16 & 0.63 & Yes & No & 120 \\
\hline 17 & 0.56 & Yes & Yes & 90 \\
\hline 18 & 0.62 & Yes & Yes & 100 \\
\hline 19 & 0.43 & Yes & Yes & 90 \\
\hline 20 & 0.40 & Yes & Yes & 90 \\
\hline 21 & 1.10 & Yes & Yes & 120 \\
\hline 22 & 0.56 & Yes & Yes & 60 \\
\hline Mean \pm Standard Deviation & $0.60 \pm 0.17$ & $22 / 22(100 \%)$ & $21 / 22(95.45 \%)$ & $95 \pm 21.10$ \\
\hline
\end{tabular}

gical field, a more efficient release and removal of adhesions between the SDFT, the PAL and the subcutaneous tissue.

The effectiveness of the PAL desmotomy regarding the return to sports activity obtained in this study (63.64\%) was similar to the results reported by Gerriing and Webon [9], with $66.6 \%$ success rate, Verschooten and Picavet [15], with $64 \%$ and McGhee et al. [10], with $57 \%$ of recovery. Moreover, the obtained data is lower than that reported by Cohen et al. [4], with $71 \%$ return to sport.

The wound suture dehiscence of the animals of G2 did not affect the time to return to sports activity, but caused significant local aesthetic damage. The results obtained with PAL desmectomy were similar to those obtained by McGhee et al. [10], using a similar technique with $100 \%$ of success. The technique used by McGhee et al. [10] had better therapeutic in relation to desmotomy and the conservative treatment associated with rest.

In this study, it is emphasized that PALD is an important affection of the musculoskeletal system of athletic horses and should be considered in the differential diagnosis of the nonresponding lesions to perineural block of the palmar nerve in the equine distal limb. Although desmectomy was more efficient in the promotion of the resolution of the injury and the return to sports activity, it showed a higher risk of dehis- cence of the suture and aesthetic damage to the wound. With the evaluated data, the PAL thickness did not affect in the return to sports, showing no correlation between the ligament thickness and the success of the surgical technique.

\section{References}

1. Alves ALG. Ultra-sonographic diagnostic of equine limbs. Rev Ed Cont CRMV-SP 1998, 1, 31-35.

2. Alves ALG, Rodrigues MAM, Aguiar AJA, Thomassian A, Nicoletti JLM, Hussni CA, Borges AS. Effects of beta-aminopropionitrile fumarate and exercise on equine tendon healing: gross and histological aspects. J Equine Vet Sci 2001, 21, 335-340.

3. Chan CC, Murphy H, Munroe GA. Treatment of chronic digital septic tenosynovitis in 12 horses by modified open annular ligament desmotomy and passive open drainage. Vet Rec 2000, 147, 388-393.

4. Cohen JM, Schneider RK, Zubrod CJ, Sampson SN, Tucker RL. Desmitis of the distal digital annular ligament in seven horses: MRI diagnosis and surgical treatment. Vet Surg 2008, 37, 336-344.

5. Dik KJ, van den Belt AJM, Keg PR. Ultrasonographic evaluation of the fetlock annular ligament constriction in the horse. Equine Vet J 1991, 23, 285-288.

6. Escodro PB. Considerations about Annular Palmar Ligament 
in equine tendon repair. Braz $\mathrm{J}$ Equine Med 2006, 2, 1824.

7. Fortier LA, Nixon AJ, Ducharme NG, Mohammed HO, Yeager A. Tenoscopic examination and proximal annular ligament desmotomy for treatment of equine "complex" digital sheath tenosynovitis. Vet Surg 1999, 28, 429-435.

8. Genovese RL, Rantanen NW, Hauser ML, Simpson BS. Diagnostic ultrasonography of equine limbs. Vet Clin North Am Equine Pract 1986, 2, 145-226.

9. Gerring EL, Webbon PM. Fetlock annular ligament desmotomy: a report of 24 cases. Equine Vet J 1984, 16, 113-116.

10. McGhee JD, White NA, Goodrich LR. Primary desmitis of the palmar and plantar annular ligaments in horses: 25 cases (1990-2003). J Am Vet Med Assoc 2005, 226, 83-86.

11. Owen KR, Dyson SJ, Parkin TDH, Singer ER, Kristoffersen M, Mair TS. Retrospective study of palmar/ plantar annular ligament injury in 71 horses: 2001-2006. Equine Vet J 2008, 40, 237-244.

12. Stashak TS. Adam's Lameness in Horses. 4th ed. pp. 618619. Roca, Sao Paulo, 1994.

13. Thomassian A. Disases of Horses. 4th ed. pp.142-143. Livraria Varela, São Paulo, 2005.

14. Turner AS, McIlwraith CW. Surgical Techniques in Large Animal. 1st ed. pp.1380-1440. Roca, São Paulo, 1985.

15. Verschooten F, Picavet TM. Desmitis of fetlock annular ligament in the horse. Equine Vet J 1986, 18, 138-142. 